\title{
ESCOLA POLITÉCNICA: POSSIVELMENTE O PRIMEIRO CURSO FORMAL DE CONTABILIDADE DO ESTADO DE SÃO PAULO
}

\author{
THE POLYTECHNIC SCHOOL: POSSIBLY THE FIRST FORMAL \\ ACCOUNTANCY COURSE IN THE STATE OF SÃO PAULO
}

\author{
ELISEU MARTINS \\ Professor Titular do Departamento de Contabilidade e Atuária \\ da Faculdade de Economia, Administração e Contabilidade \\ da Universidade de São Paulo - Campus Capital \\ E-mail: emartins@usp.br \\ AMADO FRANCISCO DA SILVA \\ Professor Ms. da Faculdade de Economia e Ciências Contábeis \\ da Universidade Metodista - SP \\ E-mail:amadof@ig.com.br \\ ÁLVARO RICARDINO \\ Professor Doutor do Departamento de Ciências Contábeis \\ da Faculdade de Economia, Administração, Contabilidade e Atuária \\ da Pontifícia Universidàde Católica de São Paulo - SP \\ E-mail: aricardino@superig.com.br
}

\section{RESUMO}

Este trabalho demonstra que, diferentemente do que se tem tanto falado, a primeira instituição formal de ensino contábil do Estado de São Paulo foi a Escola Politécnica, fundada em 1894, que ministrava no Curso Preliminar, equivalente ao primeiro ano do curso de engenharia, aulas de Escrituração Mercantil, conferindo aos alunos que fossem aprovados nas disciplinas que integravam esse primeiro módulo, o diploma de Contador. Em 08.12.1900, o Decreto Fedẹral no 727 reconhecia oficialmente os diplomas expedidos pela instituição, desde a sua fundação, independentemente do exercício da profissão. A Fundação Escola de Comércio Álvares Penteado, fundada em 1902, foi a segunda instituição voltada ao ensino contábil nesse Estado. Considerando-se um hiato de oito anos entre a fundação de ambas as instituições, não restam dúvidas de que a Escola Politécnica é a primeira instituição formal de ensino contábil do Estado de São Paulo. Não obstante, um nome surge ligado exponencialmente às duas instituições: Horácio Berlinck.

Palavras -chave: Ensino Contábil; Escola Politécnica; Escola de Comércio Álvares Penteado; Horácio Berlinck.

\section{ABSTRACT}

This study demonstrates that, as opposed to what is commonly told, the first accounting teaching institution in São Paulo state was the Polytechnic School, which was founded in 1894 and offered, as part of its Preliminary Course, equivalent to the first year of the engineering course, Mercantile bookkeeping classes, granting to students who graduated in the subjects of this first module the degree of Accountant. On 12/08/1900, Federal Decree $n^{\circ} 727$ officially recognized the degrees issued by the institutions since the time of its foundation, independently from whether the profession was exercised. The Álvares Penteado School of Commerce Foundation, which was founded in 1902, was the second institution oriented towards accounting teaching in that State. In view of an eight-year gap between the founding of the two institutions, it is beyond doubt that the Polytechnic School is the first accounting teaching institution in São Paulo State. Nevertheless, one name is important at both institutions: Horácio Berlinck.

Keywords: Accounting Teaching; Polytechnic School; Álvares Penteado School of Commerce; Horácio Berlinck. 


\section{INTRODUÇÃO}

A falta de pesquisas voltadas à recuperação da história da Contabilidade no Brasil permite, vez por outra, que algumas afirmações se perpetuem por intermédio de contínuas referências escritas ou verbais à afirmativa original.

Um exemplo dessa natureza diz respeito à Fundação Escola de Comércio Álvares Penteado, tida e referendada, por diversos autores ${ }^{1}$, como a primeira instituição de ensino contábil no Estado de São Paulo. A esse respeito, duas notáveis exceções devem ser destacadas: Rodrigues Filho $(1980)^{2}$ e Santos (1985).

Tão grande é a convicção acerca do assunto que o ex Diretor-Presidente daquela instituição, quando das justíssimas homenagens conferidas ao Prof. Horácio Berlinck, por ocasião do $50^{\circ}$ aniversário de seu falecimento, assim se pronunciou:

Dessa capacidade [capacidade administrativa do

Prof. Berlinck] surgiram, no Brasil, os primeiros cursos de Ciências Contábeis, cursos pioneiros que se iniciaram na Escola Prática de Comércio, fundada em 1902, mais tarde transformada em Fundação Escola de Comércio Álvares Penteado. FECAP (1998, p. 10).

A afirmativa é inexata ${ }^{3}$. Em data anterior àquela, outra instituição, formalmente constituída, a Escola Politécnica de São Paulo, ensinava e outorgava diploma de Contador àqueles que concluíssem o curso preliminar, como se mostrará mais à frente.

Enfatiza-se o uso da expressão "formalmente constituída" em função de que, anteriormente à Escola Politécnica de São Paulo, outras iniciativas, comprovadas ou não, podem ser encontradas no Estado de São Paulo, porém diferem da Escola Politécnica por não fornecerem diplomas de Contabilidade reconhecidos legalmente.

\section{METODOLOGIA DE PESQUISA}

Segundo a metodologia descrita por Andrade (1995, p. 15), no que tange aos seus objetivos, este trabalho se caracteriza como pesquisa descritiva já que

os fatos são registrados, analisados, classificados e interpretados, sem que o pesquisador interfira sobre eles.

No que diz respeito às técnicas de pesquisa, foi utilizado o processo documental que classifica as fontes como primárias e secundárias. Nesse particular, foram utilizados ambos os tipos de fonte. Ainda a esse respeito, vale registrar a opinião de Spina apud Andrade (op. cit., p. 39), para quem

o termo fonte pode ser empregado como a acepção genérica, compreendendo desde os documentos originais, as obras de fundo, até a página de um almanaque (fontes gráficas).

Oportuna a menção aos almanaques, posto que parte das fontes primárias abrangeram exatamente esse material que, até onde é de conhecimento dos autores, tem sido pouco explorado pela área contábil. Guardadas as devidas proporções, os almanaques equivaliam às listas telefônicas atuais. Publicados anualmente, informavam, entre outras coisas $^{4}$, o nome e o endereço dos mais importantes habitantes da cidade onde o almanaque era publicado, bem como a profissão e/ou cargo exercidos. Tal qual as listas telefônicas, quando um novo exemplar era editado o antigo era descartado, motivo pelo qual remanescem alguns poucos almanaques nas bibliotecas e acervos particulares da cidade de São Paulo. A indicação da localização de tais publicações se baseia no exaustivo levantamento efetuado por Camargo (1983)

A identificação dos profissionais que exerciam a atividade contábil na cidade de São Paulo, na segunda metade do século XIX, tomou por base informações coletadas em alguns desses poucos exemplares.

\section{AS ORIGENS DA ESCOLA PRÁTICA DE COMÉRCIO}

Segundo publicação da própria instituição, FECAP (1998, p. 30-1), a Escola nasceu dos ideais do Prof. Horácio Berlinck que, em 1897, convenceu seu amigo particular, Dr. João Pedro da Veiga Filho, a pleitear junto ao governo da cidade de
São Paulo a criação de uma escola de comércio. A solicitação foi recusada pela Câmara Municipal por falta de verbas.

$A$ alternativa seguinte foi buscar recursos junto à iniciativa privada. Reunindo o aporte financeiro de diversos

\footnotetext{
1 Permitimo-nos não referenciá-los.

2 Queremos agradecer ao Prof. Masayuki Nakagawa a indicação do trabalho de Rodrigues Filho. Foi o ponto de partida que inspirou a realização deste artigo.

3 Importante esclarecer que este trabalho não põe em dúvida ou questiona os enormes e irrefutáveis méritos da instituição e/ou das pessoas que para ela trabalharam ou vêm trabalhando ao longo desse mais de um século de inegáveis serviços ao País e à Contabilidade, em particular. O que aqui se propõe é, tão somente, a revisão do pioneirismo nesse campo.

4 Feriados, datas religiosas, horário de chegada e saída do correio etc.

5 Os autores agradecem àquela autora a indicação e cessão da obra referenciada.
} 
industriais e banqueiros da época, em 02 de junho de 1902 era fundada a Escola Prática de Comércio de São Paulo. No dia 15 daquele mês, tiveram início as aulas da primeira turma, composta por 216 alunos regularmente matriculados. A 09 de janeiro de 1905, o Decreto Federal o 1.399 reco- nhecia oficialmente os diplomas expedidos. No dia $1^{\circ}$ de dezembro do mesmo ano, a instituição passou a denominar-se Escola de Comércio de São Paulo, atual Fundação Escola de Comércio Álvares Penteado.

\section{AS PRIMEIRAS INSTITUIÇÕES DE ENSINO DE SÃO PAULO}

Segundo Almeida (2000, p. 285-6), o Estado de São Paulo, em 1889, possuía 1.573 .000 habitantes, dos quais apenas 1,6\% tinham acesso à educação. Naquela ocasião, havia apenas cinco instituições formais que forneciam instrução secundária: o Liceu de Artes e Ofícios de São Paulo, o Instituto Taubateano de Agricultura, Artes e Ofícios, o Colégio São Miguel e o Colégio Perseverança, em Guaratinguetá. No campo do ensino superior, o Estado contava apenas com a Faculdade de Direito, situada no Largo de São Francisco.

O pioneirismo do ensino contábil no Estado de São Paulo apresenta alguns aspectos controvertidos. Almeida (2000) e os sites das duas instituições que permanecem desde aquela época ${ }^{6}$ confirmam que nenhuma das cinco instituições ministrava o ensino comercial ou mantinha aulas de Contabilidade. A ausência de educação contábil, naquele período, também é confirmada por Moacyr (1939, p.311-435). Não obstante, a curta biografia do Prof. Horácio Berlinck, apresentada no trabalho comemorativo dos 100 Anos da Fundação Escola de Comércio Álvares Penteado, indica que, em 1895, "[...] Ramos de Azevedo o fez professor de Contabilidade do Liceu de Artes e Ofícios". Gordinho (2002, p. 33). A mesma publicação faz constar que, em 1893, João Pedro da Veiga Filho foi convidado a lecionar Finanças e Contabilidade Pública na Academia de São Paulo, atual Faculdade de Direito da USP. Ainda que o Liceu de Artes e Ofícios e a Faculdade de Direito incluíssem em seus currículos tal disciplina, ambas as instituições não outorgavam aos seus alunos o diploma de Contador, motivo pelo qual, sem desmerecer seus esforços, não são reconhecidas como instituições de formadores dessa categoria profissional.

Duas outras referências a cursos de Contabilidade no Estado de São Paulo vêm, respectivamente, de Almeida (2000, p. 148) e Mancini (1978).

A primeira dá conta do propósito da Sociedade Culto à Ciência, fundada em 1874, de constituir, assim que sua situação financeira permitisse, uma Escola de Agricultura e um curso de Contabilidade Comercial. Em que pese a importância de tais propósitos, o site da instituiçãa ${ }^{7}$, na página dedicada à sua história, não contém qualquer referência à concretização daquele ideal. A criação de ambos os cursos, até onde se sabe, ficou apenas na intenção.

A segunda indicação diz respeito ao trabalho pioneiro do engenheiro Estanislau Kruszynski ${ }^{8}$ que, tendo trocado a Polônia pelo Brasil, se estabeleceu na cidade de São Carlos, onde, entre os anos de 1884 e 1924, data de seu falecimento, ministrou aulas de Contabilidade em sua residência, à Rua Marechal Deodoro, no 101. Segundo Mancini (1978, p. 1-2), Kruszynski

[...] iniciou, entre nós, a tarefa de formar técnicos em contabilidade agrícola, mercantil e industrial, criando um curso de contabilidade segundo os métodos e processos em uso na Itália. Era um curso rápido de um ano e por isso cuidava de dedicar-se insistentemente ao ensino das regras essenciais dos vários sistemas de escrituração e, especialmente, o método das partidas dobradas e da personalização das contas denominada (sic) 'logismografia', sistema de contabilidade cuja concepção é a de que existem duas contas fundamentais - a do proprietário e a de terceiros (agentes consignatários e correspondentes).

Aos melhores alunos era reservado o direito de trabalhar no escritório de contabilidade de Kruszynski que cuidava da contabilidade de, pelo menos, doze fazendas da região.

Também nesse caso, em que pesem os indiscutíveis méritos do Prof. Kruszynski, que teve entre seus alunos o admirável Carlos de Carvalho, seu curso não funcionava como uma instituição de ensino oficialmente reconhecida, o que foge ao escopo deste trabalho.

\section{OS PRIMEIROS CONTADORES DA CIDADE DE SÃO PAULO}

Ainda que não houvesse cursos formais na área contábil, doze profissionais exerciam a profissão de Guarda Livros como indicado na publicação "Indicador de São Paulo para o ano de 1878" $\bullet$.
Em 1884, os Guarda-livros sediados na cidade de São Paulo eram 45 (Almanaque Administrativo para 1883, p. 349), em 1885 o número se reduziria a 40 (Almanaque Administrativo para 1884 , p. 230) e em 1886, com nova

\footnotetext{
6 Liceu de Artes e Ofícios de São Paulo e Faculdade de Direito de São Paulo.

7 www.planeta.terra.com.br/educacao/CultoaCiencia/crono.htm

8 Os autores agradecem ao Sr. Carlos Honório Martins de Oliveira a gentileza da cessão do livro sobre a vida de Estanislau Kruszynski.
} 


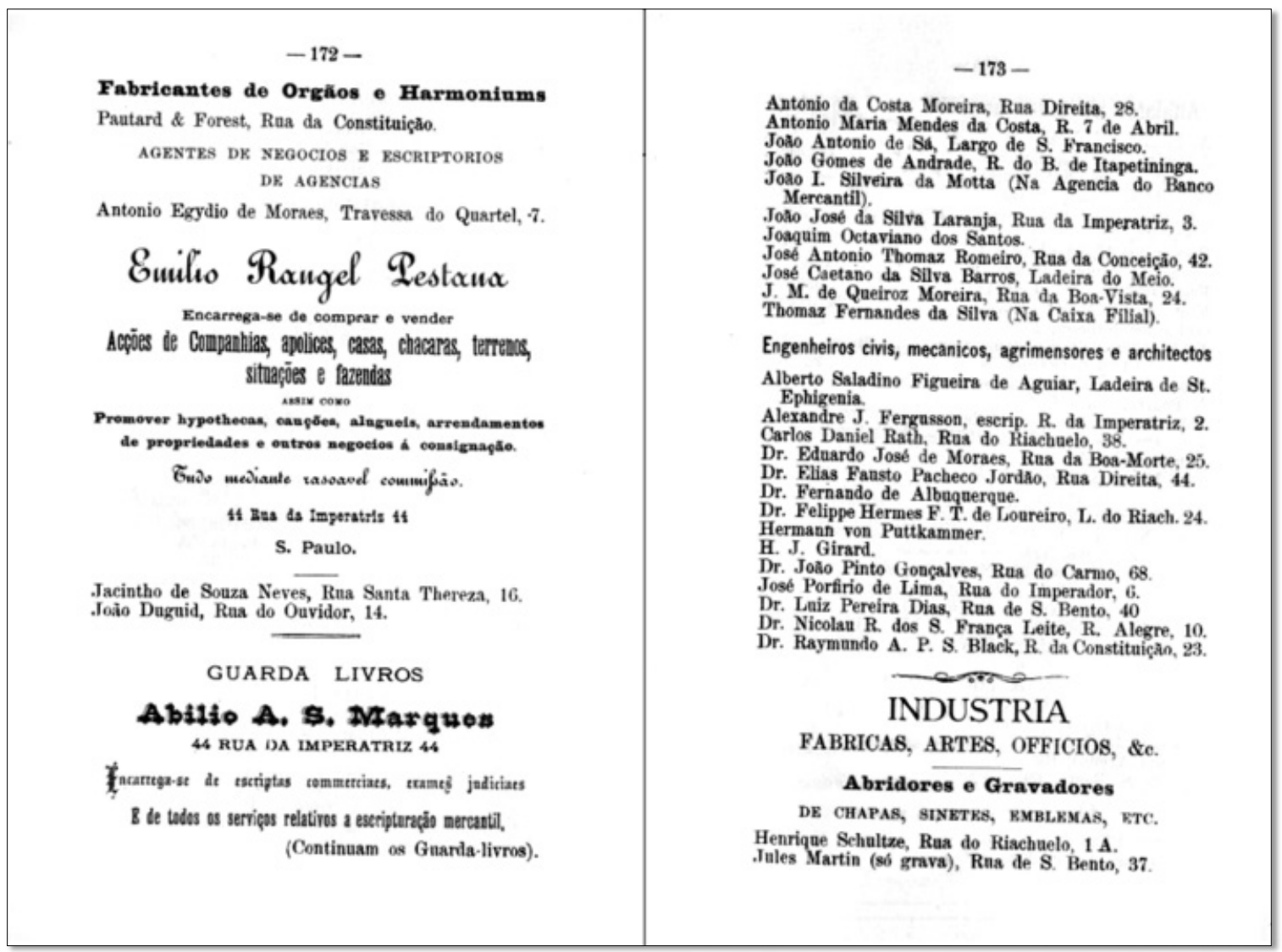

Marques (2000, p. 172-3)

redução, eram 21 os profissionais de Contabilidade na cidade (Almanaque Administrativo para 1886, p. 197). Em 1891, o número de Guarda-livros voltaria a aumentar sendo 39 os profissionais indicados pelo Almanaque Administrativo (1890, p. 188)

Dada essa evidência e se até então a Cidade de São Paulo não possuía escolas comerciais ou outras que ensinassem Contabilidade, vale perguntar: qual a fonte do conhecimento adquirido por esses pioneiros?

É difícil fornecer uma resposta precisa, mas três hipóteses, como mínimo, podem ser consideradas:

a) Aprendizado na Aula de Comércio em Lisboa: desde 1759, Portugal, por iniciativa do Marquês de Pombal, mantinha a Aula de Comércio, curso destinado a preparar homens de negócios e Contadores, tanto para o setor público quanto para o privado. Rodrigues, Gomes e Craig (2003, p. 6) indicam que, no período compreendido entre 1759 e 1794, a Aula graduou aproximadamente mil estudantes sendo que, desses, vinte e sete provinham do Brasil. Como a Aula continuou a existir até 1844, é razoável supor que, além desses, outros estudantes oriundos do Brasil foram formados em data posterior a 1794, assim como estudantes de origem portuguesa possam ter se transferido para cá. b) Aprendizado nas escolas de comércio brasileiras em outros Estados: a sociedade brasileira, ao longo do século XIX, ligava os trabalhos manuais e mecânicos aos afazeres dos escravos e classes mais humildes, criando entraves ao ensino profissionalizante, inclusive o ligado à administração dos negócios.

Formar-se doutor era ter a possibilidade de subir no status social e econômico, mas tornar-se fabricante, negociante ou lavrador era situação não desejável para a maioria dos jovens. Essas profissões eram destinadas aos menos inteligentes ou deserdados da fortuna [...]. Bielinski (2002, p. 2).

Embora tais atividades possuíssem alto grau de rejeição, diversas escolas de comércio prosperaram em alguns Estados do país.

I. A primeira delas, derivada da Aula de Comércio portuguesa, instalou-se no Maranhão, em 1811, tendo se mantido até 1820. A Aula foi reiniciada com outro professor, em $1832^{9}$.

II. Cursos Comerciais no Estado do Rio de Janeiro: diversos cursos prosperaram naquele Estado, principalmente próximo e depois da metade do século XIX, 
a começar pela Aula de Comércio da Corte, em 1846. Posteriormente, por volta de 1851, algumas instituições particulares ministravam, junto com a instrução primária, cursos preparatórios para o comércio. Eram elas: o Lyceu Commercial, na Rua do Andarahy, Collegio São Sebastião, em Botafogo, Collegio João Henrique Freese, em Nova Friburgo e Collegio Estrela de Petrópolis, em Petrópolis. Bielinski (op. cit., p. 3). Em 1856, a Aula de Comércio da Corte foi convertida no Instituto Comercial da Corte e durou até 1882, porém sem lograr o sucesso desejado. No ano de 1877 , surgiu um outro Instituto Comercial, com sede na Rua do Regente $n^{\circ}$ 19, mas não há notícias de sua continuidade. Bielinski (2002, p. 4).

III. Curso Comercial do Imperial Liceu de Artes e Ofícios do Rio de Janeiro: de todos, a tentativa mais bem sucedida. Algumas razões foram fundamentais para o seu sucesso: era gratuito e, diferentemente de seus predecessores, funcionava em horário noturno. Sua primeira turma recebeu surpreendentes 478 candidatos à matrícula. Era mantido pela SPBA - Sociedade Propagadora das Belas Artes. Ainda, no final daquele século, surgiram o Instituto Comercial do Rio de Janeiro, criado pelo Decreto 꾸 98, de
1894 e extinto em 1902. No mesmo ano de 1894 se estabeleceu o Instituto Comercial do Distrito Federal, na Praça da Aclamação, no 2410.

c) Aprendizado prático junto a estabelecimentos comerciais ou industriais: a prática era razoavelmente freqüente e dois expoentes da história brasileira tiveram os primeiros contatos com a Contabilidade como aprendizes em empreendimentos comerciais ou industriais. O primeiro foi Irineu Evangelista de Souza, Barão de Mauá, que tendo entrado como balconista de uma loja atacadista, no Rio de Janeiro, aos quatorze anos já sabia contabilizar quaisquer transações, passando à função de Guarda-livros da empresa na qual trabalhava ${ }^{11}$. O segundo, figura de proa da Contabilidade brasileira, foi Horácio Berlinck que, aos vinte e poucos anos de idade, começou a trabalhar na Fábrica Penteado, onde aprendeu Contabilidade com o Contador da empresa David Justice, profissional de origem escocesa. Fundação Escola de Comércio Álvares Penteado (2002, p. 32). Este trabalho voltará à vida de Horácio Berlinck no tópico 6, Escola Politécnica de São Paulo e Escola de Comércio Álvares Penteado: um elo comum.

\section{AS ORIGENS DA ESCOLA POLITÉCNICA DE SÃO PAULO ${ }^{12}$}

O primeiro regulamento da Escola foi outorgado pela Lei Estadual nº 191, de 24.08.1893. Na ocasião, a Politécnica foi definida como uma escola superior de matemática e ciências aplicadas às artes e indústrias. O regulamento instituiu dois tipos de cursos: o de formação de mão-deobra técnica e o superior para formação de engenheiros.

Um ano depois, em 20.11.1894, foi baixado o Decreto no 270-A instituindo o $2^{\circ}$ Regulamento. Nele foi fixada a existência de dois cursos fundamentais: o curso preliminar, com duração de um ano e o curso geral, com duração de dois anos. O objetivo de ambos era dar formação básica que permitisse melhor aproveitamento dos cursos superiores de engenharia.

Para incentivar a freqüência aos cursos fundamentais, a Congregação definiu diferentes graus de profissionalização aos estudantes que cursassem esses três anos. "Desse modo, os alunos habilitados no curso preliminar auferiam o título de Contador ${ }^{13}$ (Decreto no 270-A, art. 205)". Santos (op. cit., p. 118)

O currículo do Curso Preliminar, em 1894, era composto das seguintes disciplinas:

Matemática elementar (revisão e complementos); Trigonometria retilínea e esférica e álgebra superior; Rudimentos de geometria analítica e geometria descritiva;
Escrituração mercantil;

Desenho a mão livre e geometria elementar.

A introdução de uma disciplina voltada à Contabilidade, em um curso de engenharia, não era inovadora. Em 1890, a Escola Politécnica do Rio de Janeiro já contava em seu currículo com a disciplina Direito Administrativo e Contabilidade. Schmidt (1996, p. 363).

Os alunos que fossem aprovados nas cadeiras de Física Experimental, Meteorologia, Topografia, Elementos de Geodésia e Astronomia, bem como nas aulas de Desenho Topográfico e Elementos de Arquitetura recebiam o título de Agrimensor. Os alunos que completassem os três anos básicos recebiam, adicionalmente, o título de Engenheiro Geógrafo.

A equiparação da Escola à suas congêneres do Rio de Janeiro e Ouro Preto deu-se com o Decreto Federal no 727 , de 08.12.1900. Esse decreto é particularmente importante, pois reconhecia oficialmente os diplomas expedidos pela instituição. Assim, todos aqueles que concluíram o curso preliminar, desde a sua fundação, foram oficialmente reconhecidos como Contadores, independentemente do exercício da profissão. Portanto, comparativamente à Escola de Comércio de São Paulo e em termos de reconhecimento

\footnotetext{
10 As informações sobre a instituição foram resumidas do texto disponibilizado no site http://www.senac.br/informativo/BTS/263/boltec263e.htm, em 03/10/2004 às 15:00h. 11 Sobre a vida de Mauá, vide, entre outros Caldeira (1995)

12 As informações que aqui se reproduzem foram obtidas, fundamentalmente de Santos (1985)

13 O grifo não consta do original.
} 
oficial, um hiato de pouco mais de quatro anos ${ }^{14}$ confere à Escola Politécnica o pioneirismo do ensino contábil no Estado de São Paulo, bem como se configura como o primeiro estabelecimento de ensino do país a conceder o diploma de Contador, "antes mesmo das escolas de Comércio em 1902”. Santos (op. cit., p. 272).

A Politécnica manteve a concessão desse título até o ano de 1918, quando o Decreto Estadual oo 2931 a extinguiu. Ao longo desses vinte e quatro anos de atividades (1894-1918), a Escola Politécnica prestou um relevante serviço à Contabilidade brasileira, tornando-se parte indissociável de sua história. Nesse aspecto, a disciplina de Contabilidade, juntamente com outras, constituiu o início do Departamento de Produção, que gerou o curso de Engenharia da Produção, no qual, lecionou até sua aposentadoria o Prof. Dr. Américo Oswaldo Campiglia, pessoa de renome na Contabilidade e na Auditoria brasileiras. Em 1946, a Escola Politécnica foi uma das Faculdades que constituíram a Universidade de São Paulo sendo, até hoje, uma de suas maiores Unidades.

\subsection{Os requisitos para ingressar na Politécnica}

Segundo o art. 131 dos estatutos da instituição, para se inscrever ao $1^{\circ}$ ano de qualquer curso era necessário preencher requerimento ao diretor declarando, idade, filiação e naturalidade. Ao requerimento dever-se-ia juntar:

- Comprovante de pagamento de taxa no valor de 40\$000;
- Justificação de identidade de pessoa (espécie de carta de apresentação);

- Certidão de idade, filiação, naturalidade e, na falta desses, uma justificativa;

- Atestado de vacina;

- Certidão de aprovação em português, francês, latim, inglês ou alemão, geografia, história do Brasil, matemática elementar, álgebra, geometria e trigonometria retilínea, desenho geométrico e elementar ou certidão de aprovação no curso do Gymnasio do Estado.

A Politécnica realizava algo parecido com o que hoje se denomina "vestibular". Para ingresso o candidato deveria prestar exame na "instrução pública da capital Federal [Rio de Janeiro, à época] ou em qualquer outro estabelecimento de instrução superior desta capital ou dos Estados, onde tais exames sejam praticados [...]". (Estatuto, art. 132).

Na cidade de São Paulo, o único estabelecimento a atender tais requisitos era a Faculdade de Direito. Vale informar que, a julgar pelos documentos obtidos junto aos arquivos da Escola Politécnica ${ }^{15}$, os exames de cada disciplina eram efetuados em diferentes ocasiões.

Um exemplo prático pode ser constatado nos quatro certificados expedidos pela Faculdade de Direito de São Paulo ao candidato Tristão Tavares de Lima Junior. O histórico de seus exames indica as seguintes datas e classificações $\boldsymbol{D}$.

O certificado expedido para o exame de cada disciplina possuía as seguintes características $\mathbf{0}$.

\begin{tabular}{|l|l|l|}
\hline Data & Disciplina & Classificação \\
\hline 23.07 .1894 & Geografia, especialmente do Brasil & Simplesmente aprovado \\
\hline 23.08 .1894 & História do Brasil & Simplesmente aprovado \\
\hline 11.01 .1895 & História Universal & Plenamente aprovado \\
\hline 12.02 .1895 & Geometria e Trigonometria & Plenamente aprovado \\
\hline
\end{tabular}

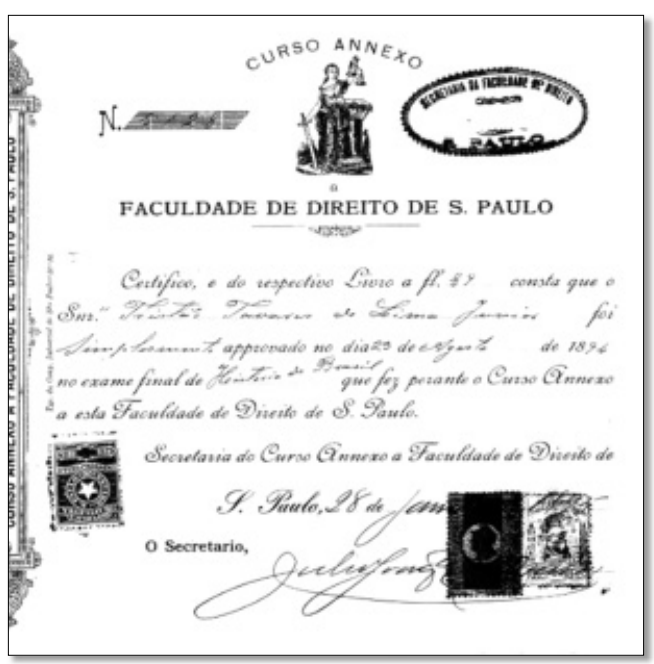

14 Os diplomas da Escola de Comércio Álvares Penteado foram oficialmente reconhecidos a partir de 09.01.1905.

15 Nesse particular, expressa-se nossa gratidão à técnica administrativa, Sra. Maria Luiza de Souza Costa, responsável pelo arquivo histórico permanente da Escola Politécnica, por toda a colaboração e apoio prestados. 
Uma vez aceito e matriculado na Politécnica, o aluno deveria cursar cinco cadeiras (disciplinas) por ano e a cada disciplina era atribuído um coeficiente a ser multiplicado pela nota obtida pelo aluno nos respectivos exames. O art. 170 dos estatutos informa que as notas eram arbitradas "por um número compreendido entre 1 e 20, por maioria de votos da comissão examinadora". A tabela de coeficientes, indicada no art. 172, § único, tinha a seguinte composição $\boldsymbol{\nabla}$.

No que diz respeito aos critérios concernentes à aprovação em cada ano, eles estão expostos no art.173: "O produto do coeficiente pela nota do exame dará o número de pontos atingidos pelo aluno; e a soma dos produtos parciais classificará as provas do ano, observadas as regras seguintes":

De 500 a 650 pontos, corresponderá à nota "simplesmente";

De 651 a 800 pontos, corresponderá à nota "plenamente";
De 801 a 950 pontos, corresponderá à nota "distinção";

De 951 a 1.000 pontos, corresponderá à nota "grande distinção".

A cada ano cursado o aluno recebia, ao término, um boletim com a indicação das notas obtidas. Um exemplo do modelo de boletim é o do aluno Tristão Tavares de Lima Junior, reproduzido abaixo $\mathbf{0}$. Destaque para a nota 11 obtida na disciplina Aula de Escrituração Mercantil, equivalente a 5,5, nos dias de hoje, nota não mais do que sofrível, mas que o habilitava a receber o certificado de Contador.

No ano de 1897, o referido aluno desligou-se da instituição, após concluir as disciplinas que lhe outorgavam, adicionalmente, o título de Agrimensor $\mathbf{0}$.

Embora os títulos conferidos pela Politécnica somente passassem a ter reconhecimento oficial a partir de 1900, no período de 1895 a 1900 a instituição formou setenta e sete alunos e todos eles, como mínimo, completaram o Curso Preliminar, ou seja, fizeram jus ao título de Contador.

\begin{tabular}{|c|c|c|c|c|c|}
\hline Disciplina & 10 ANO & 2० ANO & 3 ANO & $4^{\circ}$ ANO & 5o ANO \\
\hline $1^{\text {a }}$ Cadeira & 9 & 10 & 9 & 9 & 12 \\
\hline $2^{\text {a } C a d e i r a ~}$ & 9 & 9 & 10 & 12 & 12 \\
\hline $3^{a}$ Cadeira & 10 & 9 & 11 & 10 & 10 \\
\hline $4^{a}$ Cadeira & 12 & 12 & 10 & 9 & 6 \\
\hline $\begin{array}{l}\text { Desenho, trabalhos gráficos ou } \\
\text { projetos e exercícios práticos. }\end{array}$ & 10 & 10 & 10 & 10 & 10 \\
\hline Total & 50 & 50 & 50 & 50 & 50 \\
\hline
\end{tabular}
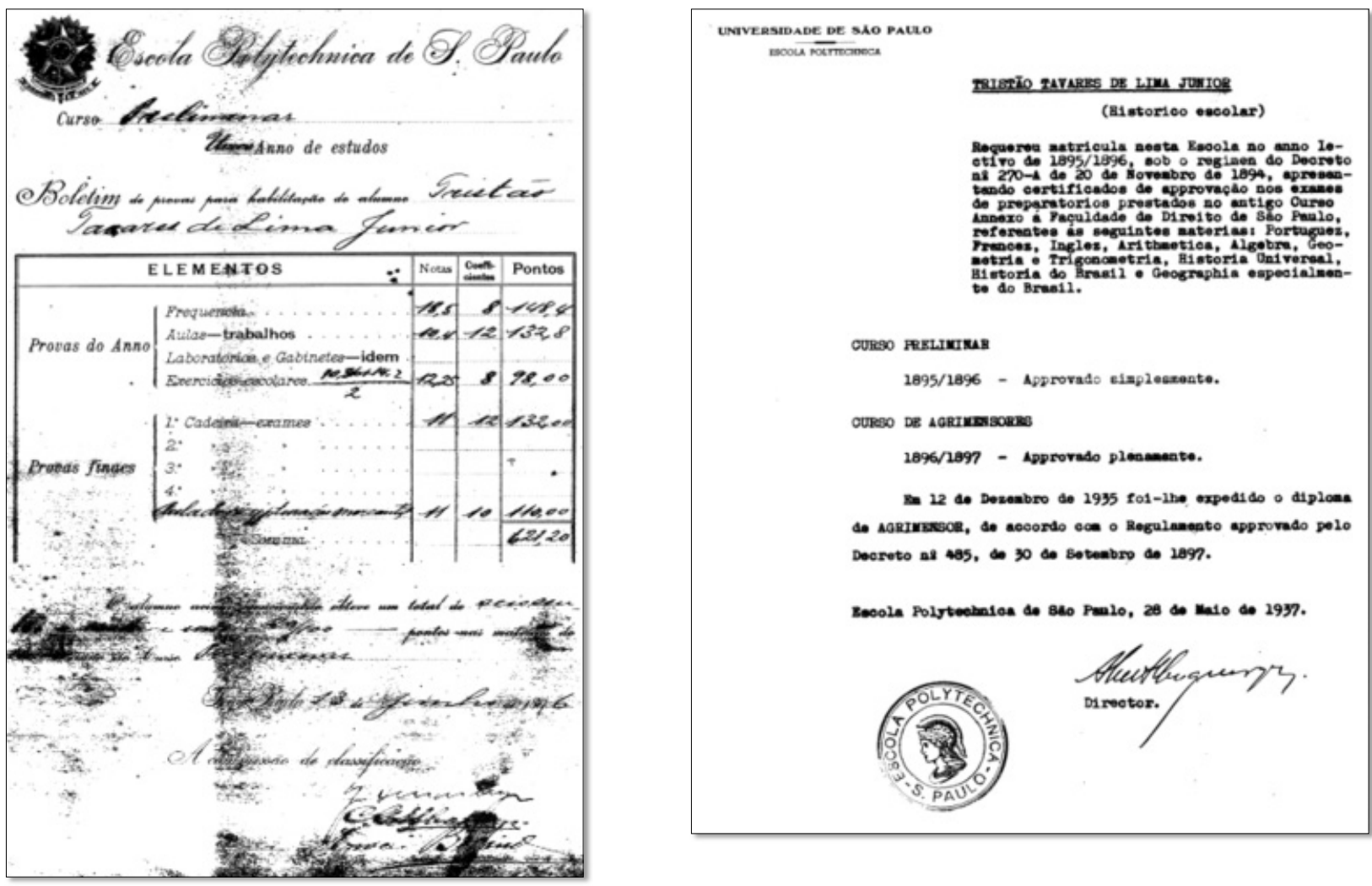


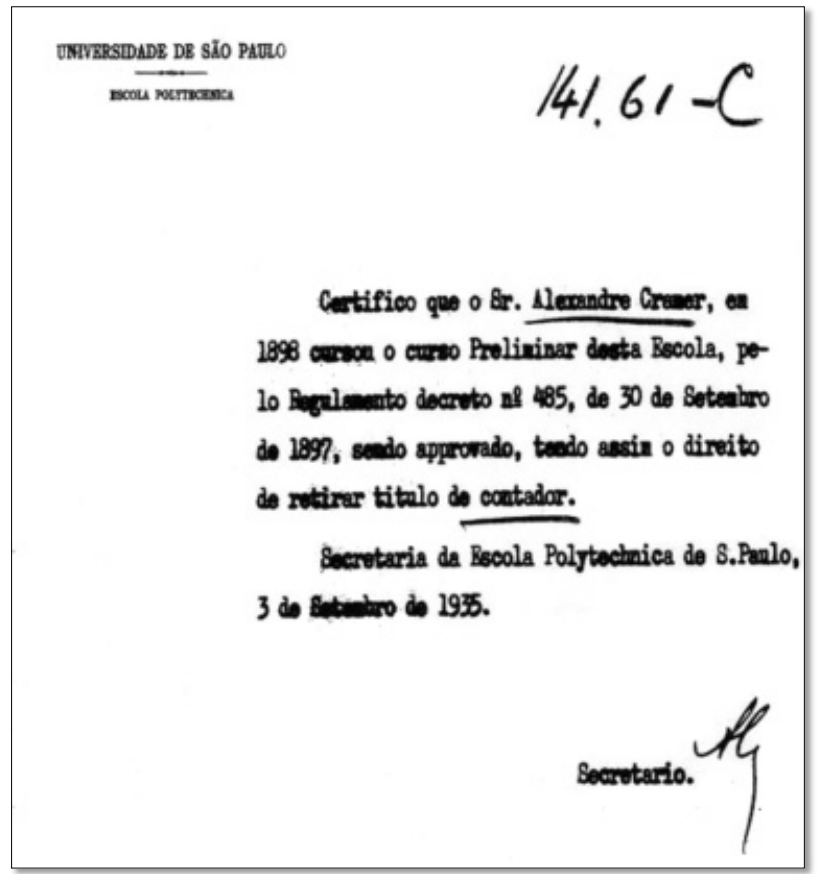

\begin{tabular}{|l|c|}
\hline Profissão & Quantidade \\
\hline Engenheiro & 26 \\
\hline Contador & $-0-$ \\
\hline Outras Profissões & 6 \\
\hline Não localizados & 45 \\
\hline Total & 77 \\
\hline
\end{tabular}

Algumas dessas pessoas só vieram a requerer seu certificado anos mais tarde, como foi o caso do aluno Alexandre Cramer, alemão, nascido em 11.10.1854. Formou-se agrimensor em 23.07.1898. Exerceu essa atividade em Rio Claro, cidade em que foi residir após se formar. Requereu seu certificado de Contador trinta e sete anos depois de formado, em 03.09.1935, aos oitenta e um anos de idade.

As consultas a almanaques, anuários, à obra Personagens de Nossa História e, principalmente, ao site Google, fornecem algumas indicações da carreira profissional seguida pelos setenta e sete alunos que concluíram o primeiro ano do curso nos seis primeiros anos de funcionamento daquela instituição.

Como indicado no quadro acima, dos 32 localizados nenhum parece ter seguido a carreira contábil, porém, em função do elevado número de estudantes cujos nomes não foram localizados, não se pode afirmar que tal não tenha ocorrido.

\section{ESCOLA POLITÉCNICA DE SÃO PAULO E ESCOLA DE COMÉRCIO ÁLVARES PENTEADO: UM ELO COMUM}

O primeiro professor da aula de Escrituração Mercantil da Escola Politécnica de São Paulo foi Horácio Berlinck $^{16}$, admitido na instituição em 05.01.1895. Em 1896, publicou a obra Contabilidade Aplicada às Empresas Comerciais, Industriais, Agrícolas e Financeiras, em cuja página inicial constata-se sua condição de professor daquela instituição. Vide destaque na lateral da reprodução $\bullet$
Como informado anteriormente, em 02 de junho de 1902, Berlinck fundou a Escola Prática de Comércio de São Paulo, primeira instituição exclusivamente voltada ao ensino comercial no Estado de São Paulo. A 09 de janeiro de 1905, o Decreto Federal no 1339 reconheceu oficialmente os diplomas expedidos pela Escola Prática de Comércio. A 1o de dezembro do mesmo ano, a instituição passou a chamar-se Escola de Comércio de São Paulo, sendo que, em 1908, a 


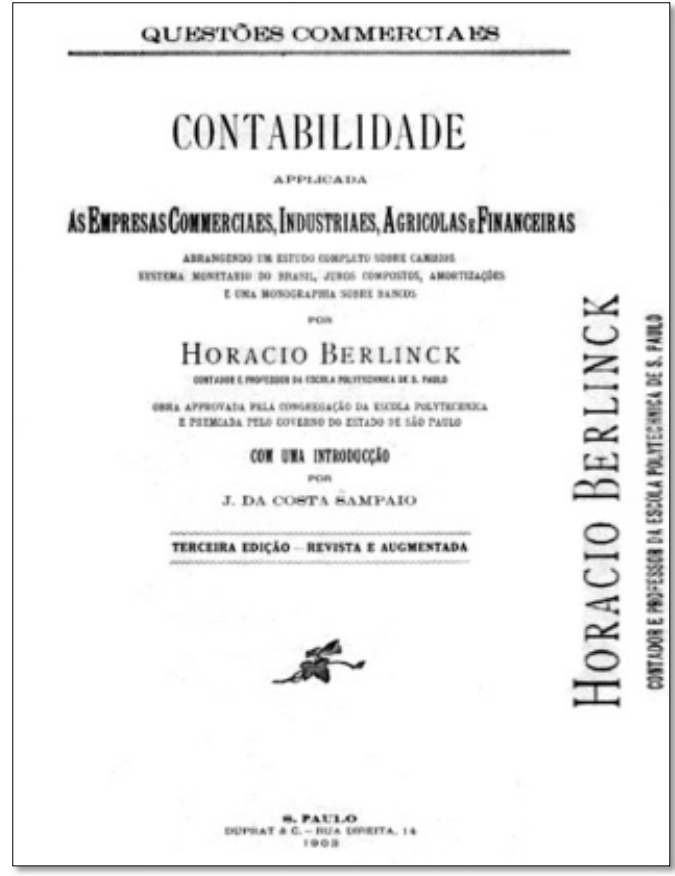

Escola ampliava suas metas e criava o Curso Superior de Ciências Comerciais, interrompido em 1914, por ocasião da I Guerra Mundial. O curso foi reaberto em 1932, com o nome de Faculdade de Ciências Econômicas de São Paulo.

Não obstante a envergadura da empreitada, ela não afastou o docente de seus alunos da Escola Politécnica. Pelo contrário, Berlinck lecionou naquela instituição até

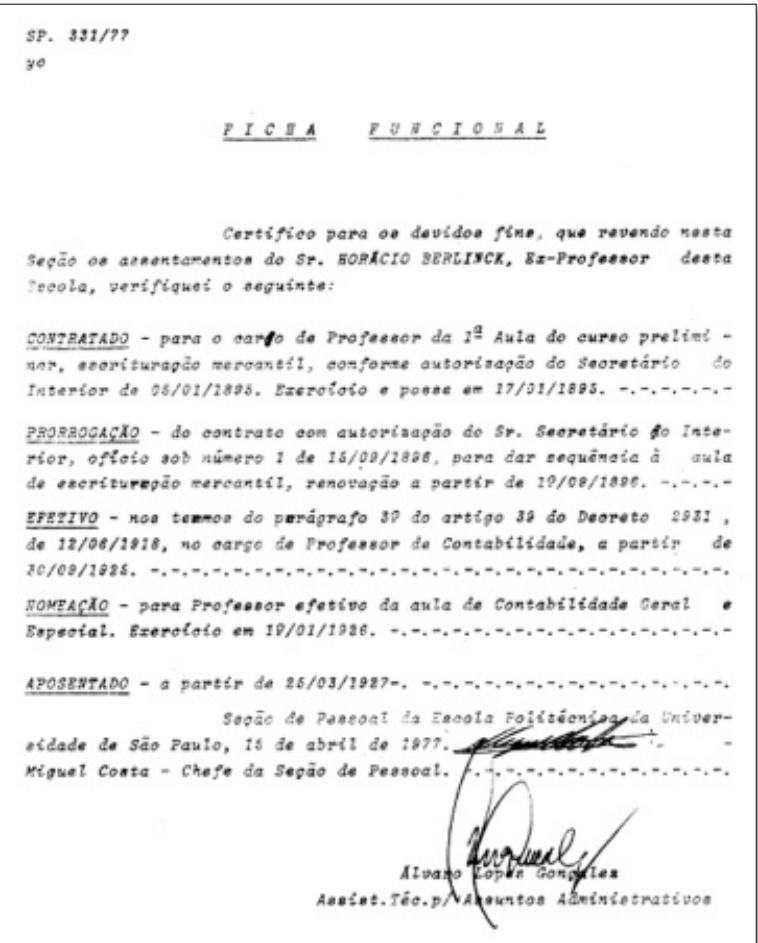

1927, ano em que se aposentou, conforme demonstra seu histórico profissional $\mathbf{0}$, emitido pela instituição.

Horácio Berlinck legou às gerações seguintes, além do seu pioneirismo, diversas obras ${ }^{17}$. Faleceu em 20 de setembro de 1948, constituindo-se num dos principais vultos da Contabilidade brasileira, em todos os tempos.

\section{CONCLUSÃO}

Muitos escritos e a tradição oral vêm consagrando a Escola de Comércio Álvares Penteado como a primeira instituição de ensino da Contabilidade no Estado de São Paulo, mas tal assertiva não é correta. Antecedendo-a em aproximadamente oito anos, a Escola Politécnica de São Paulo conferia o título de Contador aos alunos que concluíssem o Curso Preliminar, certificação que passou a ser reconhecida oficialmente a partir de 1900 , portanto dois anos antes do início das atividades da Escola Prática de Comércio de São Paulo.

Até aquela data, setenta e sete alunos adquiriram o direito legal de exercer a profissão contábil, muito embora as pesquisas sobre as respectivas carreiras não tenham indicado que algum deles tenha exercido a profissão contábil.

Ainda que a Escola de Comércio Álvares Penteado não seja, de fato, a primeira instituição de ensino contábil no Estado de São Paulo, um denominador comum as une: o Prof. Horácio Berlinck. Primeiro professor da aula de Escrituração Mercantil foi, também, fundador da Escola de Comércio Álvares Penteado. De per si, qualquer um desses feitos seria suficiente para imortalizá-lo, porém, tomados em conjunto, elevam-no, para sempre, ao panteão dos maiores da Contabilidade em nosso país. 


\section{Referências Bibliográficas}

ALMANACH ADMINISTRATIVO, COMMERCIAL E INDUSTRIAL DA PROVÍNCIA DE SÃO PAULO, para o ano bissexto de 1884. São Paulo: Ed. Jorge Seckler \& Cia., 1883.

ALMANACH ADMINISTRATIVO, COMMERCIAL E INDUSTRIAL DA PROVÍNCIA DE SÃO PAULO, para o ano de 1885. São Paulo: Ed. Jorge Seckler \& Cia., 1884.

ALMANACH ADMINISTRATIVO, COMMERCIAL E INDUSTRIAL DA PROVÍNCIA DE SÃO PAULO, para o ano de 1886. São Paulo: Ed. Jorge Seckler \& Cia., 1885.

ALMANACH DO ESTADO DE SÃO PAULO PARA 1891. São Paulo: Ed. Jorge Seckler \& Cia., 1890.

ALMEIDA, José Ricardo Pires de. Instrução Pública no Brasil (1500-1889): história e legislação, São Paulo: Educ - Editora da PUC-SP, 2000.

ANDRADE, Maria Margarida de. Como preparar trabalhos para cursos de pós-graduação. São Paulo: Atlas, 1995.

BIELINSKI, Alba Carneiro. Educação Profissional no Século XIX - Curso Comercial do Liceu de Artes e Ofícios: um estudo de caso. Site www. senac.br/informativo/BST/263/boltec263e.htm, 29/11/2002.

CADERNOS ALVARES PENTEADO, Uma vida a serviço de um ideal, FECAP, Intróito Mestre dos Mestres, Oliver Gomes da Cunha, 1998.

CALDEIRA, Jorge, Mauá, empresário do Império. São Paulo: Companhia das Letras, 1995.

CAMARGO, Ana Maria de Almeida. Os primeiros almanaques de São Paulo, São Paulo: convênio IMESP/DAESP, 1983.

GORDINHO, Margarida Cintra. Coordenação e textos. FECAP: 100 ANOS. São Paulo: Editora Marca D’Água Ltda., 2002.

http://www.senac.br/informativo/BTS/263/boltec263e.htm em 03/10/2004 às 15:00h.

MANCINI, José. Estanislau Kruszynski. São Carlos: Editora Indústria e Comércio Gráfico “O Expresso”, 1978.

MARQUES, Abílio A. S. Indicador de São Paulo, Administrativo, Judicial, Industrial, Profissional e Comercia, l para o ano de 1878. Edição Facsimilar, São Paulo: convênio IMESP/DAESP, 2000.

MOACYR, Primitivo. A Instrução e as Províncias: subsídios para a história da educação no Brasil, 1835-1889, $2^{\circ}$ vol, Sạ̃o Paulo: Companhia Editora Nacional, 1939.

RICARDINO, Álvaro. “A Metafísica da Contabilidade Comercial e a História das Aulas de Comércio”, I Congresso USP de Controladoria e Contabilidade, Anais do seminário, Publicado em CD - 10 páginas, Universidade de São Paulo, 01 a 02/10/2001.

RODRIGUES, Lúcia Lima. GOMES, Delfina. CRAIG, Russel. The Portuguese School of Commerce, 1759-1844. The Third Accounting History International Conference, Anais do Congresso, Siena, 2003.

RODRIGUES Filho, Antônio Peres. A Evolução do Ensino Comercial no Brasil e a Formação do Contador (Auditor, Controlador e PeritoContábil) na Universidade de São Paulo, São Paulo 1980.

SANTOS, Maria Cecília Loschiavo dos. Escola Politécnica (1894-1984). São Paulo: USP, 1985.

SCHMIDT, Paulo. Uma Contribuição ao Estudo da História do pensamento Contábil. São Paulo, 1996. Tese (Doutoramento) - FEA - USP, Faculdade de Contabilidade.

\section{NOTA - Endereço dos autores}

Universidade de São Paulo

Faculdade de Economia, Administração e Contabilidade

Departamento de Contabilidade e Atuária

Av. Prof. Luciano Gualberto, 908 - Cidade Universitaria

São Paulo - SP

05508-900

Universidade Metodista

Faculdade de Economia e Ciências Contábeis

Rua Alfeu Tavres, 149 - Rudge Ramos

São Bernardo do Campo - SP

09641-000
Pontifícia Universidade Católica de São Paulo

Faculdade de Economia e Adminstração

Rua Monte Alegre, 984 - Perdizes

São Paulo - SP

05014-001 